\title{
Urine as a specimen to diagnose infections in twenty-first century: focus on analytical accuracy
}

\section{Tamara Tuuminen ${ }^{1,2 *}$}

${ }^{1}$ Department of Bacteriology and Immunology, Haartman Institute, University of Helsinki, Helsinki, Finland

${ }^{2}$ Mikkeli District Laboratory, Eastern Finland Laboratory Centre Joint Authority Enterprise, Mikkeli, Finland

\section{Edited by:}

Hao Shen, University of Pennsy/vania School of Medicine, USA

\section{Reviewed by:}

Adrianus Wilhelmus Maria Van Der Velden, Stony Brook University, State

University of New York, USA

Guoku Hu, Creighton University, USA

Shijun Zheng, China Agricultural

University, China

\section{${ }^{*}$ Correspondence:}

Tamara Tuuminen, Department of Bacteriology and Immunology, Haartman Institute, University of Helsinki, P.O. Box 21, Helsinki 00014 Finland.

e-mail: tamara.tuuminen@helsinki.fi; tamara.tuuminen@islab.fi
Urine as a clinical specimen to diagnose infections has been used since ancient times. Many rapid technologies to assist diagnosis of infections are currently in use. Alongside traditional enzyme immunoassays (EIA), new technologies have emerged. Molecular analysis of transrenal DNA to diagnose infections is also a rapidly growing field. The majority of EIAs utilize the detection of excreted sugar compounds of the outer microbial cell-wall shed into the bloodstream and excreted into the urine. This mini-review focuses on current knowledge on rapid urinary antigen detection tests to diagnose most common infections, and highlights their diagnostic utility. The past and the future of urinalysis are also briefly discussed. The analysis of the literature shows that some methods are not quantitative, and analytical sensitivity may remain suboptimal. In addition, the performance criteria and technical documentation of some commercial tests are insufficient. Clinical microbiologists and physicians should be alert to assay limitations.

Keywords: urinalysis, urine, parasites, bacteria, viruses, fungi, immunochromatographic methods, ELISA

\section{URINE AS A SPECIMEN}

Milleniums ago urine as a diagnostic specimen attracted the attention of early physicians. The history of uroscopy and urinalysis starting from the time of Pharaonic Egypt has been reviewed (White, 1991; Eknoyan, 2007). In Egypt and Aztec cultures urine was used to disinfect wounds and was rubbed into the skin to treat cuts and burns (Aztecs at Mixicoloro by Bernard Ortiz de Montellano, Wayne State University, USA; Available at: http://www.mexicolore.co.uk/index.php?one $=a z t \& t w o=h e a)$. In medical papyri (1550 BCE) of ancient Egypt hematuria was described using hieroglyphic symbols. This condition was most probably caused by the worm Schistosoma haematobium (Papyrus, 1875) that plagued people living along the Nile Valley (Ruffer, 1910).

A Greek philosopher, naturalist, and the Roman emperor's physician, Claudius Galenos (129-200 CE) used the humoral philosophy of ancient Greece which was based on the concept of Hippocrates (460-370 BCE). According to Hellenistic teaching the body is at equilibrium or homeostasis when four juices are in balance. Urine was one of the four pillars of the galenic humoral pathology. Centuries later this teaching was reintroduced in Europe during the Renaissance.

Urine is an ideal clinical specimen for diagnostics because it is excreted in large quantities and collection does not require invasive methods. When conventional culture remains either negative or unreliable, diagnosis of systemic infectious disease based on the demonstration of bacterial antigens directly from urine has many potential advantages. If the kidneys are intact, the excreted urinary antigens have a lower MW than of albumin $(<67 \mathrm{kDa})$ or for transrenal DNA usually do not exceed $100 \mathrm{bp}$ (Green et al., 2009).

This mini-review describes several methods for some important infections, with the aim to illustrate their analytical utility. Regarding the extent of the contemporary literature it cannot be comprehensive.

\section{URINE RAINBOW}

Inspection of the color of urine is still useful today (Foot and Fraser, 2006). Unusual color comprising practically the whole spectrum of the rainbow is associated with various metabolic or infectious diseases. Below are illustrated only a few examples where the color of the urine is almost pathognomonic for a specific infection.

\section{RED COLOR, OR HEMATURIA}

Hematuria is a condition of the presence of fresh blood in urine. This symptom is found in a great variety of non-infectious disorders but may also occur in relation to common infections, e.g., urinary tract infection (UTI). It may follow the prodromal period (Katayama syndrome) after infection with Schistosoma haematobium ( $\mathrm{CDC}^{1}$, WHO: schistosomiasis ${ }^{2}$ ). Hematuria may also be a symptom in viral zoonotic infections that may lead to hemorrhagic fever with renal syndrome (HFRS). HFRS are caused by, e.g., Hantaan, Dobrava, Seoul viruses, or other arboviruses, e.g., Yellow Fever Disease, Rift Valley Fever, or tick-borne Crimea-Congo Hemorrhagic Fever, or Dengue virus that may cause Hemorrhagic Fever (DHF; WHO: Dengue ${ }^{3}$ ).

\section{BROWN COLOR, OR BLACK WATER FEVER AND OTHER INFECTIONS}

Black water fever is a urological manifestation of malaria caused by Plasmodium falciparum. The color of urine turns brownish due

\footnotetext{
${ }^{1}$ www.cdc.gov/parasites/schistosomiasis/gen_info/faqs.html

${ }^{2}$ http://www.who.int/mediacentre/factsheets/fs115/en/index.html

${ }^{3}$ http://www.who.int/mediacentre/factsheets/fs117/en/
} 
to profuse hemoglobinuria. The brownish color of urine could be observed also in cholestasis with jaundice that may occur, e.g., in hepatitis A virus infection or in leptospirosis, a zoonotic disease, caused by the spirochete Leptospira interrogans.

\section{MILKY COLOR, OR CHYLURIA}

Chyluria, or "milky urine", is a symptom of the disturbance of lymphatic flow that may be caused by filariasis. A tapeworm, Wuchereria bancrofti, accounts for $90 \%$ of human filariasis and is widespread across tropic and subtropic areas (Kehinde et al., 2008).

\section{INFLAMMATORY MARKERS FROM URINE}

A non-specific immune marker, neopterin, produced by human macrophages has been detected from urine as well as blood. This marker was found elevated in several inflammatory diseases and in AIDS (Fuchs et al., 1989). Recently, pro-inflammatory chemokines and cytokines have been studied in urine from patients with pulmonary tuberculosis (TB). Only IP-10 was excreted in the urine in measurable quantities exceeding those of patients without TB (Cannas et al., 2010).

\section{TESTS FOR HISTOPLASMOSIS}

Progressive disseminated histoplasmosis ( $\mathrm{PDH})$ is common in persons with AIDS, and other immunosuppressed patients (Kauffman, 2008). Antigen detection in plasma or urine is a significant adjunct to clinical and other diagnostic methods. The most frequently reported test is the enzyme immunoassay (EIA) developed by MiraVista Diagnostics (Indianapolis, IN, USA) which has been recently refined (Wheat et al., 2007). This method detects circulating polysaccharides of Histoplasma capsulatum and provides quantification of antigen concentration. A quantitative assay that can measure the polysaccharide down to $0.6 \mathrm{ng} / \mathrm{ml}$ (range $0.6-39$ ) was recently reported (Connolly et al., 2007). The manufacturer of another commercially method, IMMY ALPHA (ImmunolMycologics, Inc., Norman, Oklahoma, USA), claims similar performance although some authors reported controversy (McKinsey et al., 2009).

Antigenuria is a sensitive laboratory biomarker of Histoplasma clearance and was used to monitor the efficacy of antimycotic treatment (Hage et al., 2011a). On the other hand, positive urine antigen levels may persist at low levels for months in patients without clinical illness (Kauffman, 2008). In a large evaluation in cases with acute pulmonary histoplasmosis (APH) the sensitivity of both urine and blood detection methods was equal, being positive in $64.6 \%$ (antigenuria) and $68.6 \%$ (antigenemia; Swartzentruber et al., 2009). Combined, these tests reached a sensitivity of $82.8 \%$ but, combined with the antibody detection method, the sensitivity was $93.3 \%$ (Swartzentruber et al., 2009). In culture positive patients with PDH the sensitivity of the ELISA urine method was higher but still suboptimal, $81 \%$, but the specificity in healthy persons and non-histoplasmosis disease reached 95\% (Scheel et al., 2009). In a multicenter evaluation the sensitivity of antigen test was proportional to disease severity, 91.8\% in $\mathrm{PDH}$ and only $30.4 \%$ in subacute histoplasmosis (Hage et al., 2011b). It was presumed that antigenuria should be greater and, thus, more readily detectable in patients with a high fungal burden such as in
AIDS patients with PDH (sensitivity 90\%) than in other patients (e.g., pulmonary forms, sensitivity 75\%; Kauffman, 2008). This observation corroborates the findings from TB studies when urinary lipoarabinomannan (LAM) was detected more readily from AIDS patients than from others. Similarly to pneumococcal antigen detection methods, ultrafiltration of urine was suggested to improve sensitivity (Srinivasan et al., 2009). As expected, due to structural similarities of polysaccharides from other dimorphic fungi (Blastomyces dermatitidis, Coccidioides immitis, Paracoccidioides brasiliensis, and Penicillium marneffei) some interference from cross-reactivity has been documented (Kauffman, 2008).

\section{OTHER URINARY TESTS FOR DISSEMINATED MYCOSES}

In invasive aspergillosis chest $\mathrm{x}$-ray, computer tomography, culture, and microscopy may not always lead to diagnosis. The commercial Platelia ${ }^{\mathrm{TM}}$ Aspergillus ELISA detects galactomannan from Aspergillus spp. The method was tested with 105 samples from hematological patients using sera, urine, or bronchoalveolar lavage. Serum and urine analyses were positive in 14 and $5 \%$ of samples, respectively. Ten-fold concentration of urine increased the number of positive samples to $8 \%$. In six patients with confirmed invasive aspergillosis the antigen was detected in serum, but only in two was the urine test positive, suggesting serum is a preferred sample for screening (Salonen et al., 2000).

A urine test to detect $B$. dermatitidis antigen (Durkin et al., 2004) has a sensitivity of $92 \%$ (in pulmonary and in disseminated forms and good specificity in healthy volunteers but interference from cross-reactivity occurred in $96.3 \%$ of patients with histoplasmosis, $100 \%$ in paracoccidioidomycosis, $70 \%$ in penicilliosis, and very low cross-reactivity in patients with cryptococcosis and aspergillosis (Durkin et al., 2004).

Another capture-based EIA detects antigens from C. immitis (Durkin et al., 2009). This test was applied both to serum and urine. The authors claimed that they were able to measure galactomannan from urine samples at concentrations down to $0.07 \mathrm{ng} / \mathrm{ml}$ yielding clinical sensitivity of $50 \%$.

In summary, results of tests for fungal antigenuria are promising. However, the clinical relevance of some methods is difficult to reproduce by outside laboratories because they are proprietary to the companies (Scheel et al., 2009).

\section{STREPTOCOCCUS PNEUMONIAE POLYSACCHARIDES IN URINE}

Despite availability of pneumococcal vaccines, Streptococcus pneumoniae is the number one causative agent of community acquired pneumonia (CAP), sepsis, and meningitis. The diagnostic utility of excreted soluble urine antigen in patients with pneumonia was first described in 1917 (Dochez and Avery, 1917). Current diagnostic aids have been recently reviewed (Klugman et al., 2008). According to the authors the sensitivity of all methods to identify S. pneumoniae in CAP remains inadequate. Bacterial isolation from patients with pneumococcal CAP was successful from less than 20\% (Klugman et al., 2008) to 37.5\% (Marcos et al., 2003). Urinary diagnostics can be a useful adjunct to culture. A positive result is highly indicative of $S$. pneumoniae as the causative agent in adults but less so in infants due to microbial colonization in their nasopharyngeal cavity (Klugman et al., 2008). The urinary test is based on the detection of polysaccharide $\mathrm{C}$ common in all clinically 
significant serogroups. For example, immunochromatographic membrane assay (ICT) Binax ${ }^{\circledR}$ NOW S. pneumonia Urinary Antigen Test (ME, USA) using blood culture as the gold standard for positives displayed a sensitivity of $86-90 \%$ and specificity $71-94 \%$, the latter being dependent on the study cohort. In a large study (Marcos et al., 2003) the sensitivity reached $100 \%$ in patients with definitive pneumococcal pneumonias and $69.2 \%$ in patients with probable pneumonia, whereas in patients without pneumococcal pneumonia a false positive rate of $18 \%$ was observed. These authors further advocated the use of concentrated urine; however, they did not clearly address the issue of specificity. The Binax ${ }^{\circledR}$ NOW provides qualitative antigen identification and analytical sensitivity is expressed in terms of colony forming units/ml which is not relevant to the quantities of excreted antigen in terms of concentration. Concerning specificity, the manufacturer reported that urine from patients with UTI displayed variable interference $(9 \%)$ resulting in invalid result interpretations. Interestingly, urine collected from persons without signs of UTI may also occasionally test false positive although culture negative. The reason for this interference is presently obscure. One possibility is that the cross-reactivity is produced by thus far uncharacterized host inflammatory reaction compounds or alimentary components, rather than bacterial constituents.

The issue of urine concentration remains highly controversial. The manufacturer recommends the use of non-concentrated urine, but some researchers (Domínguez et al., 2001; Marcos et al., 2003) claimed that a 25-fold urine concentration may provide increased sensitivity. In a large prospective evaluation (Marcos et al., 2003) concentrated urine resulted in a 1.4-fold increase in positives detected (from 38 to $53 \%$ ). However, large prospective evaluation (Murdoch et al., 2001) using concentrated urine increased positive detection only marginally (from 29 to $30 \%$ ) in CAP patients.

Based on ultrafiltration experiments the size of the $\mathrm{C}$ polysaccharide of approximately $20-30 \mathrm{kDa}$ was suggested (Murdoch et al., 2001). Pioneering work performed at The Rockefeller Institute (NY, USA) in the early 1960s (Gotschlich and Liu, 1967) characterized the polysaccharide $\mathrm{C}$ extracted from bacterial culture. Later, (Sørensen et al., 1990; Karlsson et al., 1999) the polysaccharide $\mathrm{C}$ was studied in details. Still unresolved is the size and the chemical composition of the antigen that is excreted into the urine.

\section{LEGIONELLA PNEUMOPHILA POLYSACCHARIDES IN URINE}

Suspicion of nosocomial or community acquired legionellosis warrants immediate diagnosis and differentiation from other pathogens because the infection requires antibiotic treatment different from that used in pneumococcal infection.

There are several commercial urinary antigen detection tests on the market, the majority being developed for the clinically most important Legionella pneumophila serogroup 1. For example, Binax ${ }^{\circledR}$ Now Legionella Urinary Antigen Test (Inverness Medical) is a ICT with a low interference (5\%) in cohorts of bacterial pneumonia, sepsis, and UTI. When the three ICT antigen detection tests were compared using 39 unfrozen and non-concentrated urine samples from patients with Legionnaire's disease, the sensitivities were $74.3,61.5$, and $41 \%$ for the Binax ${ }^{\circledR}$ Now, the SAS ${ }^{\mathrm{TM}}$ Legionella
Test (SA Scientific Inc.) and the Uni-Gold ${ }^{\mathrm{TM}}$ Legionella Urinary Antigen Plus (Trinity Biotech; Muñoz et al., 2009). However, recent comparison of the Binax ${ }^{\circledR}$ NOW ICT to two EIA methods resulted in superior EIA performance. This retrospective study was performed on 178 frozen urine samples. The authors found that with non-concentrated urine samples the sensitivity levels of $71.3 \%$ for the Bartels Legionella Urinary Antigen (Trinity Biotech); $65.1 \%$ for Biotest Legionella Urine Antigen EIA (now marketed by BioRad) and $37 \%$ for Binax ${ }^{\circledR}$ NOW. After concentration, however, significant differences in sensitivity no longer existed (Guerrero et al., 2004). The specificity issues of concentrated vs. non-concentrated samples are presently unrecognized.

A systematic review and meta-analysis assessed the performance of EIA-based and ICT urine antigen detection methods (Shimada et al., 2009). The authors concluded (Shimada et al., 2009) that higher quality studies had lower sensitivity, and a publication bias was evident. In their summary the pooled sensitivity of urinary methods to detect infection with L. pneumophila, serotype 1 was $74 \%$ (95\% CI, 68-81\%), and the specificity was $99.1 \%(95 \%$ CI, 98.4-99.7\%).

As a matter of fact, the origin of the test antigen is not reported in commercial protocols; however, from its strict serogroup specificity one may assume that it is lipopolysaccharide (LPS), a heatstable antigen present in all Gram-negative bacteria. Chemical analysis of Legionella LPS was performed decades ago (Conlan and Ashworth, 1986), but the size and the chemical composition of the excreted polysaccharide are not yet known.

\section{LAM FROM URINE TO ASSIST DIAGNOSIS OF TUBERCULOSIS}

Tuberculosis is a global health emergency of enormous proportions. The major obstacles to TB control is the lack of fast, affordable, and accurate diagnostic techniques both for pulmonary and extrapulmonary TB in adults and children (Peter et al., 2010; Yasinskaya et al., 2011). One approach is to detect the presence of urinary microbial metabolites, e.g., LAM.

Lipoarabinomannan is a structural heat-stable cell-wall glycolipid of Mycobacterium tuberculosis. It constitutes up to $15 \%$ of the total bacterial weight. LAM is a virulence factor and is released from metabolically active or degrading $M$. tuberculosis in TB infection. The size of this polymeric structure is variable, being on the average $17.5 \mathrm{kDa}$ (range 6-34; Chatterjee, 1997; Brennan, 2003; Nigou et al., 2003). The first detection of urinary LAM was described a decade ago (Hamasur et al., 2001). An earlier commercial method (Chemogen Inc., Portland, ME, USA), is presently marketed as the Clearview ${ }^{\text {TM }}$ TB ELISA (Inverness Medical Innovations). A meta-analysis and systemic review of the diagnosis of TB using this reagent reported estimates of sensitivity and specificity in microbiologically confirmed cases (seven studies) of 13-93 and 87-99\%, respectively (Minion et al., 2011). In five studies with results stratified by HIV status, the sensitivity was $3-53 \%$ but in HIV + ve subgroups it was systematically higher and the highest sensitivity was observed in advanced immunosuppression. In a large prospective evaluation including 141 patients with definitive $\mathrm{TB}$ and 172 patients with no proven TB, urine LAM test was positive in only $17 / 141$ and $1 / 172$, respectively (Dheda et al., 2010). In this study the sensitivity in HIV + ve patients was $21 \%$ and in 
those whose CD4+ cell counts were below $200 \mathrm{cell} / \mathrm{mm}^{3}$ the sensitivity reached $37 \%$; the specificity being $95-100 \%$ (Dheda et al., 2010). Reported data have shown that better diagnostic utility is associated with advanced stages of HIV infection and low CD4+ cell count (Dheda et al., 2010). This observation is explained by an assumption that in TB with AIDS as co-morbidity, bacterial burden is higher compared to cases without AIDS. Amazingly, extensive clinical evaluations (Minion et al., 2011) have been performed using the Clearview ${ }^{\mathrm{TM}}$ TB ELISA without confirmation that LAM is, in fact, excreted in urine of TB patients. No evidence is apparent also for LAM as the analyte detected by the polyclonal antibodies is the LAM indeed. As in the S. pneumoniae urine detection method cross-reactivity with possibly structurally non-related substances is observed. This finding may further lead to speculation that mechanisms of assay interference could be common for assays of this type where polyclonal antibodies are used.

\section{URINE AS A SAMPLE TO STUDY VIRAL INFECTIONS}

Human polyomaviruses (HPyVs) are widespread and unique to humans. High quantities of viral particles can be shed in urine from a healthy individual. In nephropathy, e.g., after kidney transplantation, in profound immunosuppression or in AIDS, in hemorrhagic cystitis (BKV), or in symptoms of central nervous system compatible with progressive multifocal leucomyelopathy (JCV), these viruses may no longer be "innocent bystanders" (Kumar, 2010). NAATs for both urine and blood have been developed to detect, subtype, and estimate viral loads.

Congenital cytomegalovirus (CMV) infection, a leading cause of sensorineural hearing loss and neurological impairment (Cannon et al., 2011), can be robustly detected directly from urine. In primary infections CMV is excreted and can be cultured from urine for several weeks.

Urine has been utilized as sample for the early diagnosis of Dengue virus infection. In some situations urine NAATs provided greater sensitivity than does analysis of plasma (Poloni et al., 2010). Virus-specific IgG or IgA-class antibodies as serological markers of this disease have been also detected in urine (Vazquez et al., 2007).

\section{URINE AS A SAMPLE TO DIAGNOSE SEXUALLY TRANSMITTED DISEASES}

Urine is extremely useful to diagnose infections of the reproductive tract. The recent systematic review (Cook et al., 2005) on non-invasive testing for Chlamydia trachomatis and Neisseria gonorrhoeae showed that both assays reached specificities of $97 \%$ for both infections and in both sexes. However, for chlamydial infection the pooled sensitivities were: $83.3,92.5$, and $79.9 \%$ for PCR, transcription-mediated amplification and strand displacement amplification assays in women and $84,87.7$, and $93.1 \%$ in men, respectively. For the gonococcal infection the respective sensitivities in women were 55.6, 91.3, and $84.9 \%$. Therefore, PCR for gonococcal infection in women performed from urine was not recommended (Cook et al., 2005).

\section{REFERENCES}

Banday, K. M., Pasikanti, K. K., Chan, E. C., Singla, R., Rao, K. V. S., Chauhan, V.S., and Nanda, R. K. (2011). Use of urine volatile organic components to discriminate tuberculosis patients from healthy subjects. Anal. Chem. $83,5526-5534$.

The newly developed triple assay for the simultaneous detection of C. trachomatis, N. gonorrhoeae, and Mycoplasma genitalium (Dx CT/NG/MG assay BioRad, USA) may provide more evidence about the role of $M$. genitalium in sexually transmitted diseases (STDs). This smallest human bacterium has been earlier associated with non-gonococcal urethritis in men but now also in low-risk women. M. genitalium is considered a cause of urethritis, mucopurulent cervicitis, and upper genital tract infections like pelvic inflammatory disease and even infertility (McGowin and Anderson-Smits, 2011; Weinstein and Stiles, 2011).

\section{EMERGING TECHNOLOGIES AND PATHOGENS}

Flow cytometry-based analysis (FACS) that quantifies both bacteria and white blood cells in the urine has emerged as a promising diagnostic tool (Jolkkonen et al., 2010). Gas chromatography/mass spectrometry to detect volatile organic components in human urine has been recently described although not yet implemented in clinical practice (Banday et al., 2011). Detection of microbial transrenal DNA is an attractive option to diagnose infections (Green et al., 2009). The authors, however, cited concerns about lack of standardization of methodology both for pre- and analytical steps, storage, and transportation of the sample. A nested PCR from urine and saliva to detected trace amounts of Plasmodium DNA has been described (Putaporntip et al., 2011). The sensitivity of the urine method was two to fourfold less than that shown for saliva, but the combination of both biological fluids displayed a sensitivity superior to that of microscopy. Moreover, double malarial infections could be easily detected.

As new detection technologies emerge, knowledge about new pathogens continues to increase. For example, Actinobaculum schaalii may cause undiagnosed cystitis predominantly in the elderly and in those persons in whom the primary focus appears to be anomalies in the genitourinary tract (e.g., benign prostatic hyperplasia). Most recently it has been associated with bloodstream infections (Beguelin et al., 2011). Urine FACS may prove useful to identify less known or unknown pathogens which can be suspected on the basis of discrepancy between conventional culture and a positive fluorescence signal denoting "presence" of bacteria.

\section{CONCLUSION}

In the future urine, because of ease of collection, processing, and storage, may be extensively used for targeted multiplexed analyses. Current state-of-the-art, however, indicates that some detection methods still require further understanding of molecular forms and structures detected, as well as the excretion kinetics of these polymeric compounds.

\section{ACKNOWLEDGMENTS}

I want to thank Dr. Kari Lounamo for valuable comments on the manuscript and my friend Dr. Jeffrey Travis for revision of this manuscript. This work is dedicated to the memories of my father professor of immunology Evgeny Stanislavsky and professor of biotechnology Christian Oker-Bloom.

Beguelin, C., Genne, D., Varca, A., Tritten, M. L., Siegrist, H. H., Jaton, K., and Lienhard, R. (2011). Actinobaculum schaalii: clinical observation of
20 cases. Clin. Microbiol. Infect. 17, 1027-1031.

Brennan, P. J. (2003). Structure, function, and biogenesis of the cell wall of 
Mycobacterium tuberculosis. Tuberculosis (Edinb). 83, 91-97.

Cannas, A., Calvo, L., Chiacchio, T., Cuzzi, G., Vanini, V., Lauria, F. N., Pucci, L., Girargi, E., and Goletti, D. (2010). IP-10 detection in urine is associated with lung diseases. BMC Infect. Dis. 10, 2-8. doi:10.1186/1471-2334-10-333

Cannon, M. J., Hyde, T. B., and Schmid, D. S. (2011). Review of cytomegalovirus shedding in bodily fluids and relevance to congenital cytomegalovirus infection. Rev. Med. Virol. 210.21, 240-255.

Chatterjee, D. (1997). The mycobacterial cell wall: structure, biosynthesis and sites of drug action. Curr. Opin. Chem. Biol. 1, 579-588.

Cook, R. L, Hutchison, S. L., Østergaard, L., Braithwaite R. S., and Ness, R. B. (2005). Systematic review: noninvasive testing for Chlamydia trachomatis and Neisseria gonorrhoeae. Ann. Intern. Med. 142, 914-925.

Conlan, J. W., and Ashworth, L. A. E. (1986). The relationship between the serogroup antigen and lipopolysaccharide of Legionella pneumophila. J. Hyg. (Lond.) 96, 39-48.

Connolly, P. A., Durkin, M. M., Lemonte, A. M., Hackett, E. J., and Wheat, L. J. (2007). Detection of histoplasma antigen by a quantitative enzyme immunoassay Clin. Vaccine Immunol. 14, 1587-1591.

Dheda, K., Davids, V., Lenders, L., Roberts, T., Meldau, R., Ling, D., Brunet, L., van Zyl Smit, R., Peter, J., Green, C., Badri, M., Sechi, L., Sharma, S., Hoelscher, M., Dawson, R., Whitelaw, A., Blackburn, J., Pai, M., and Zumla, A. (2010). Clinical utility of a commercial LAM-ELISA assay for TB diagnosis in HIV-infected patients using urine and sputum samples. PLoS ONE 5, e9848. doi:10.1371/journal.pone. 0009848

Dochez, A. R., and Avery, O. T. (1917). The elaboration of specific soluble substance by pneumococcus during growth. J. Exp. Med. 26, 477-493.

Domínguez, J., Galí, N., Blanco, S., Pedroso, P., Prat, C., Matas, L., and Ausina, V. (2001). Urinary antigen test for pneumococcal pneumonia. Chest 120, 1748-1750.

Durkin, M., Estok, L., Hospenthal, D., Crum-Cianflone, N., Swartzentruber, S., Hackett, E., and Wheat, L. J. (2009). Detection of Coccidioides antigenemia following dissociation of immune complexes. Clin. Vaccine Immunol. 16, 1453-1456.

Durkin, M., Witt, J., Lemonte, A., Wheat, B., and Connolly, P. (2004). Antigen assay with the potential to aid in diagnosis of blastomycosis. J. Clin. Microbiol. 42, 4873-4875.

Eknoyan, G. (2007). Looking at the Urine: the renaissance of an unbroken tradition. Am. J. Kidney Dis. 49, 865-872.

Foot, C. L., and Fraser, J. F. (2006). Uroscopic rainbow: modern matula medicine. Postgrad. Med. J. 82, 126-129.

Fuchs, D., Spira, T. J., Hausen, A., Reibnegger, G., Wener, E. R., Felmayer, G. W., and Wacher, H. (1989). Neopterin as a predictive marker for disease progression in human immunodeficiency virus type 1 infection. Clin. Chem. 35, 1746-1749.

Gotschlich, E. G., and Liu, T.-Y. (1967). Structural and immunological studies on the pneumococcal C polysaccharide. J. Biol. Chem. 242, 463-470.

Green, C., Huggett, J. F., Talbot, E., Mwaba, P., Reither, K., and Zumla, A. (2009). Rapid diagnosis of tuberculosis through the detection of mycobacterial DNA in urine by nucleic acid amplification methods. Lancet Infect. Dis. 9, 505-511.

Guerrero, C., Toldos, C. M, Yagüe, G., Ramírez, C., Rodríguez, T., and Segovia, M. (2004). Comparison of diagnostic sensitivities of three assays (Bartels Enzyme Immunoassay [EIA], Biotest EIA, and Binax NOW Immunochromatographic Test) for detection of Legionella pneumophila serogroup 1 antigen in urine. J. Clin. Microbiol. 42, 467-468.

Hage, C. A., Kirsch, E. J., Stump, T. E., Kauffman, C. A., Goldman, M., Connolly, P., Johnson, P. C., Wheat, L. J., and Baddley, J. W. (2011a). Histoplasma antigen clearance during treatment of histoplasmosis in patients with AIDS determined by a quantitative antigen enzyme immunoassay. Clin. Vaccine Immunol. 18, 661-666.

Hage, C. A., Ribes, J. A., Wengenack, N. L., Baddour, L. M., Assi, M., McKinsey, D. S., Hammoud, K., Alapat, D., Babady, N. E., Parker, M., Fuller, D., Noor, A., Davis, T. E., Rodgers, M., Connolly, P. A., El Haddad, B., and Wheat, L. J. (2011b). A multicenter evaluation of tests for diagnosis of histoplasmosis. Clin. Infect. Dis. 53, 448-454.

Hamasur, B., Bruchfeld, J., Haile, M., Pawlowski, A., Bjorvatn, B., Källenius, G., and Svenson, S. B. (2001). Rapid diagnosis of tuberculosis by detection of mycobacterial lipoarabinomannan in urine. J. Microbiol. Methods 45, 41-52.
Jolkkonen, S., Paattiniemi, E.-L., Kärpänoja, P., and Sarkkinen, H. (2010). Screening of urine samples by flow cytometry reduces the need for culture. J. Clin. Microbiol. 48, 3117-3121.

Karlsson, C., Jansson, P.-E., and Skov Sørensen, U. B. (1999). The pneumococcal common antigen Cpolysaccharide occurs in different forms. Eur. J. Biochem. 265, 1091-1097.

Kauffman, C. (2008). Diagnosis of histoplasmosis in immunosuppressed patients. Curr .Opin. Infect. Dis. 21, 421-425.

Kehinde, E. O., Anim, J. T., and Hira, P. R. (2008). Parasites of urological importance. Urol. Int. 81, 1-13.

Klugman, K. P., Madhi, S. A., and Albrich, W. C. (2008). Novel approaches to the identification of Streptococcus pneumoniae as the cause of community-acquired pneumonia. Clin. Infect. Dis. 47(Suppl. 3), S202-S206.

Kumar, D. (2010). Emerging viruses in transplantation. Curr. Opin. Inf. Dis. 23, 374-378.

Marcos, M. A., Jiménez de Anta, M. T, de la Bellacasa, J. P, González, J., Martínez, E., García, E., Mensa, J., de Roux, A., and Torres, A. (2003). Rapid urinary antigen test for diagnosis of pneumococcal communityacquired pneumonia in adults. Eur. Respir. J. 21, 209-214.

McGowin, C. L., and AndersonSmits, C. (2011). Mycoplasma genitalium: an emerging cause of sexually transmitted disease in women. PLoS Pathog 7, e1001324. doi:10.1371/journal.ppat.1001324

McKinsey, D. S., McKinsey, J. P., Northcutt, N., and Sarria, J. C. (2009). Interlaboratory discrepancy of antigenuria results in 2 patients with AIDS and histoplasmosis. Diagn. Microbiol. Infect. Dis. 63, 111-114.

Minion, J., Leung, E., Talbot, E., Dheda, K., Pai, M., and Menzies, D. (2011). Diagnosing tuberculosis with urine lipoarabinomannan: systemic review and meta-analysis. Eur. Respir. J. 38, 1398-1405.

Muñoz, M. J., Martínez Toldos, M. C. Yagüe, G., and Segovia, M. (2009). Evaluation of three immunochromatographic assays for detection of Legionella pneumophila serogroup 1 antigen in urine samples. Rev. Esp. Quimioter. 22, 207-209.

Murdoch, D. R., Laing, R. T. R., Mills, G. D., Karalus, N. C., Town, G. I. Mirrett, S., and Reller, L. B. (2001). Evaluation of a rapid immunochromatographic test for detection of Streptococcus pneumoniae antigen in urine samples from adults with community-acquired pneumonia. $J$. Clin. Microbiol. 39, 3495-3498.

Nigou, J., Gilleron, M., and Puzo, G. (2003). Lipoarabinomannans: from structure to biosynthesis. Biochimie 85, 153-166.

Papyrus, E. (1875). Das hermetische Buch über die Arzneimittel der alten Ägypter in hieratischer Schrift. Leipzig: Hirzel 1889.

Peter, J., Green, C., Hoelscher, M., Mwaba, P., Zumla, A., and Dheda, K. (2010). Urine for the diagnosis of tuberculosis: current approaches, clinical applicability, and new developments. Curr. Opin. Pulm. Med. 16 262-270.

Poloni, T. R., Oliveira, A. S., Alfonso, H. L., Galvão, L. R., Amarilla, A. A., Poloni, D. F., Figueiredo, L. T., and Aquino, V. H. (2010). Detection of dengue virus in saliva and urine by real time RT-PCR. Virol. J. 7, 22.

Putaporntip, C., Buppan, P., and Jongwutiwes, S. (2011). Improved performance with saliva and urine as alternative DNA sources for malaria diagnosis by mitochondrial DNAbased PCR assays. Clin. Microbiol. Infect. 17, 1484-1491.

Ruffer, M. A. (1910). Note on the presence of Bilharzia haematobia in Egyptian mummies of the twentieth dynasty (1250-1000 BC). Br. Med. J. 1,16 .

Salonen, J., Lehtonen, O. P., Teräsjärvi, M. R., and Nikoskelainen, J. (2000). Aspergillus antigen in serum, urine and bronchoalveolar lavage specimens of neutropenic patients in relation to clinical outcome. Scand. J. Infect. Dis. 32, 485-490.

Scheel, C. M., Samayoa, B., Herrera, A., Lindsley, M. D., Benjamin, L., Reed, Y., Hart, J., Lima, S., Rivera, B. E., Raxcaco, G., Chiller, T., Arathoon, E., and Gómez, B. L. (. (2009)). Development and evaluation of an enzyme-linked immunosorbent assay to detects histoplasma capculatum antigenuria in immunocompromised patients. Clin. Vaccine Immunol. 18, 852-858.

Shimada, T., Noguchi, Y., Jackson, J. L., Miyashita, J., Hayashino, Y., Kamiya, T., Yamazaki, S., Matsumura, T., and Fukuhara, S. (2009). Systematic review and metaanalysis: urinary antigen tests for Legionellosis. Chest 136, 1576-1585.

Sørensen, U. B. S., Henrichsen, J., Chen, H.-C., and Szu, S. C. (1990). Covalent linkage between the capsular polysaccharide of Streptococcus pneumoniae revealed by immunochemical methods. Microb. Pathog. 8, 325-334. 
Srinivasan, A., Kleiman, M. B., Debelenko, L., Stokes, D. C., De Vincenzo, J., and Wheat, J. L. (2009). False-negative Histoplasma antigen in acute pulmonary histoplasmosis: the value of urinary concentration by ultrafiltration and heat denaturation of serum proteins in detection of Histoplasma antigen. Pediatr. Infect. Dis. J. 28, 447-449.

Swartzentruber, S., Rhodes, L., Kurkjian, K., Zahn, M., Brandt, M. E., Connoly, P., and Wheat, L. J. (2009). Diagnosis of acute pulmonary histoplasmosis by antigen detection. Clin. Infect. Dis. 49, 1878-1882.

Vazquez, S., Hafner, G., Ruiz, D., Calzada, N., and Guzman, M. G.
(2007). Evaluation of immunoglobulin $\mathrm{M}$ and $\mathrm{G}$ capture enzyme-linked immunosorbent assay Panbio kits for diagnostic dengue infections. $J$. Clin. Virol. 39, 194-198.

Weinstein, S. A., and Stiles, B. G. (2011). A review of the epidemiology, diagnosis and evidence-based management of Mycoplasma genitalium. Sex. Health 8, 143-158.

Wheat, L. J., Witt, J., Durkin, M. Connoly, P. (2007). Reduction in false antigenemia in the second generation histoplasma antigen assay. Med. Mycol. 45, 169-171.

White, W. I. (1991). A new look at the role of urinalysis in the history of diagnostic medicine. Clin. Chem.37, 119-125.

Yasinskaya, Y., Plikaitis, B., Sizemore, C., and Sacks, L. (2011). Advancing the development of diagnostic tests and biomarkers for tuberculosis. Int. J. Tuberc. Lung Dis. 15, 985-987.

Conflict of Interest Statement: The author declares that the research was conducted in the absence of any commercial or financial relationships that could be construed as a potential conflict of interest.

Received: 27 November 2011; paper pending published: 04 January 2012; accepted: 26 February 2012; published online: 23 March 2012.

Citation: Tuuminen $T$ (2012) Urine as a specimen to diagnose infections in twenty-first century: focus on analytical accuracy. Front. Immun. 3:45. doi 10.3389/fimmu.2012.00045

This article was submitted to Frontiers in Microbial Immunology, a specialty of Frontiers in Immunology.

Copyright () 2012 Tuuminen. This is an open-access article distributed under the terms of the Creative Commons Attribution Non Commercial License, which permits non-commercial use, distribution, and reproduction in other forums, provided the original authors and source are credited. 